\title{
Special Session 4: Astronomy Education between Past and Future
}

\author{
Jean-Pierre de Greve, editor \\ Department of Physics, Vrije Universiteit Brussel, BE1050 Brussels, Belgium \\ email: jpdgreve@vub.ac.be
}

\section{Organizing committee:}

Jean-Pierre de Greve (Chair, Belgium), Rajesh Kochhar (India), Edward F. Guinan (USA), : John B. Hearnshaw (New Zealand), George K. Miley (Netherlands), Ian E. Robson (UK), Rosa M. Ros (Spain), Il Seong Nha (Rep. of Korea), Malcolm G. Smith (USA), and Antonio Videra (Brasil)

\section{Preface}

The special session aims at discussing an integrated approach of the different efforts to increase and promote the teaching and learning of astronomy in the world, with emphasis on developing countries. To this end, attention will be given to research on education, specifically in the field of physics, to best practices of the use of astronomy in educational systems (specifically in developing countries), and to innovative learning initiatives other than formal education. The Special Session aims also at creating a universal perspective wherein modern (post-Copernican) astronomy will presented as an intellectual cumulus. The objective of the session is to disseminate best practices in teaching and learning activities of astronomy and to give an opportunity to learn about initiatives in different cultural and socio-economic settings. The special session also wants to give food-for-thought and proposals for reflection for an integrative approach, and for optimization processes, to enhance the interest in astronomy and its role as a trigger towards science education in the educational systems, with emphasis on the developing countries. The outcome should be a sensitization of teachers and students alike to the concept of a universal history of astronomy and creation of some reliable source material which can be used as a teaching aid in a culture-specific context. The outcome could be a set of recommendations for future integrated actions, and eventually recommendations on new initiatives, framed into the new decadal policy plan.

Jean-Pierre de Greve, Rajesh Kochhar, Edward F. Guinan, co-chairs SOC. 